\title{
La improvisación como ruta de construcción de la obra Rascosis abordada desde la creación colectiva $\epsilon$ interdisciplinar*
}

\author{
Improvisation as construction route Rascosis work \\ approached from the interdisciplinary collective creation
}

\section{Improvisação como construção rota trabalho Rascosis abordado a partir da criação coletiva interdisciplinar}

\author{
Gustavo Zapata Ospina** \\ Universidad de San Buenaventura, Medellín, Colombia \\ Verónica Castro Carvajal ${ }^{* * *}$ \\ Universidad de San Buenaventura, Medellín, Colombia
}

ReCibido: 22 de AGOSTO de 2013 - APRobado: 21 de oCtubre de 2013

Artículo corto que presenta el avance de resultados dentro del proceso de revisión del proyecto pedagógico que se imparte de manera transversal a todos los programas de la Facultad de Educación de la Universidad de San Buenaventura, Medellín, durante el 2012.

** Licenciado en Artes Representativas de la Universidad de Antioquia y Especialista en Artes en modalidad de Teatro - Danza. Se ha desempeñado en diferentes campos de las artes escénicas como intérprete y docente, investigador, actor y bailarín. Ha participado en Colombia en talleres y seminarios dirigidos por maestros nacionales e internacionales como: Eduardo Rivero Walker, (Cuba) Hegel Letoja, Maureen Fleminng, Gilles Lipovetsky, Klaus Portl, Tuan Jhon, Beatriz Vélez, María Del pilar Naranjo, Alonso García, Cliver Barker, Juan Felipe Ortiz. Ha participado en eventos de carácter nacional e internacional como: Beca Taller Nacional de danza contemporánea, Festival Internacional de danza de Barranquilla. Ganador de la pasantía nacional de danza contemporánea 2005 Ministerio de Cultura de Colombia, I festival Internacional de danza contemporánea en Paisajes Urbanos 2001 sobresaltos, V Temporada Internacional de Danza Medellín 2001. Festival Universitario ASCUNCULTURA Regional Antioquia IV Encuentro Nacional de Escuelas Superiores de Teatro, director General grupo de danza Contemporánea Universidad de Antioquia Programa de Teatro 2001-2003. Ha sido jurado en diferentes festivales artísticos en Medellín y Antioquia. Producción artística: UNO (2002), DOS (2003), NOCHE (2004), TRANSICIÓN (2007); Adaptación de Crónica de una muerte anunciada (2012), RASCOSIS (2012), XERSES (2013), METASTASIS (2013). Coreógrafo acto conmemorativo 20 Años facultad de Artes 2000, espectáculo de inauguración jornadas académicas Universidad de Antioquia 200 AÑOS (2003); apertura I Festival Internacional de danza Contemporánea en Paisajes Urbanos (bailarín). En la actualidad se desempeña como docente de cátedra de la Facultad de Artes en la Universidad de Antioquia y en la Universidad San Buenaventura en la Facultad de Educación. E-mail: zapataospinagustavo@gmail.com

*** Maestra en Artes Plásticas y Visuales de la Universidad Distrital Francisco José de Caldas, Bogotá Colombia; se ha desempeñado como Docente de Cátedra de las Facultades de Artes Integradas y Educación de la Universidad de San Buenaventura, Medellín; ha colaborado como jurado externo de proyectos de grado de la Universidad de Antioquia. Miembro del comité organizador de los Encuentros de Experiencias Significativas en Educación Artística y Tallerista de Ediarte S.A. Actualmente cursa estudios de Maestría en Dibujo en la Universidad de Granada, España. E-mail: veronikation@gmail.com 
"Lo que determina mi proceso creativo son los hechos exteriores, la vida"

Pina Bausch

Resumen. La improvisación como motor de la puesta en escena es considerada el vínculo unificador de los sistemas escénicos, sus características fluctúan desde la libre creación hasta las técnicas de composición, así se construye ésta como traducción, instrumento e intuición que materializa corpóreamente la interioridad del ser en un cronotopo. De la disección de la unidad artística devienen códigos escénicos interdependientes: el ritmo, la composición, el espacio, el movimiento, la forma, y el tema; la intersección de dichos códigos da a luz la producción escénica.

Palabras clave. Danza contemporánea, improvisación, cuerpo, sistemas escénicos, creación colectiva (Tesauro Unesco).

Abstract. Improvisation, seen as the engine of the mise-en-scene, is considered the unifying link of the performance systems, ranging from ad lib to composition techniques, and it therefore constructs itself as a translative and intuitive tool which corporeally materializes the inner-being as a chronotope. As the artistic unit is dissected, interdependent scenic codes are derived: rhythm, composition, space, movement, shape, and theme. The intersection of these codes gives birth to the stage production.

Keywords. Contemporary dance, improvisation, body, stage systems, collective creation (Thesaurus Unesco).

Resumo. Improvisação motor como encenação é considerado o sistema de teste de links unificadores, suas características vão desde a criação de técnicas de composição livre e constrói como tradução e intuição instrumento incorporando corporalmente interioridade do ser em um chronotope. Dissecção da artísticas unidade cênica tornaram códigos interdependentes: ritmo, composição, espaço, movimento, forma e tema, o cruzamento destes códigos dá a produção de palco de nascimento.

Palavras chave. A dança contemporânea, improvisação, corpo, sistemas de palco, criação coletiva (Tesauro Unesco). 


\section{Introducción}

El arte tiene el poder de trascender la vida de quien lo participa. Permea todas las dimensiones del hombre y es el fenómeno que somete cada acción, pensamiento y materia a un proceso donde se subliman las esencias. Incluso lo básico tiene espacio en él, abandona allí su planicie para potenciar la forma y el contenido que proyecta.

El arte es el camino que existe hacia la complejización de la vida, por ello, es de suma importancia experimentar una educación artística de calidad que replantee el arraigado paradigma de la manualidad como desarrollo artístico prioritario, y por el contario, que sea promotora de nuevos modelos de vida y comprensiones del mundo. En este sentido, la dimensión artística debería soportar más carga de la que ahora resiste en el mundo educativo, de ser así se trazaría con mayor legibilidad el camino hacia su dignificación en las instituciones y en la vida de quienes participan en ella.

Por esta razón, los sujetos encargados de orientar ese proceso vital en cualquier individuo, deben movilizar su ser y atender al llamado de la reflexión antes que idealizar y buscar un maestro tipificado. Porque el arte es estar vivo y requiere su experiencia para pensar en un docente integral realmente capacitado para liderar el encuentro estético de otros.

Desde hace cuatro semestres el curso de proyecto pedagógico que se imparte de manera transversal a todos los programas de la Facultad de Educación de la Universidad de San Buenaventura, Medellín, ha requerido una mutación racional dentro la licenciatura en educación artística y cultural en su naturaleza misma como espacio donde se articulan el saber especifico y la experiencia docente. Una revisión exhaustiva de los productos generados desde el programa antes de la nueva forma de asumir el curso, reveló la desarticulación de los procesos académicos de los estudiantes y el ejercicio docente a los que se enfrentaban simultáneamente. Es así como el primer semestre de 2012 buscamos un mecanismo metodológico que brindase herramientas de cualificación a través de la interdisciplinariedad en la educación. De allí surge la articulación de los cursos Puesta en Escena, Trabajo de Grado 1, Proyectos Pedagógicos $X$ y XI, cuya línea transversal devendría en la obra Rascosis. 
Sea importante exaltar que los lineamientos teórico-conceptuales desde los cuales se construyó la propuesta fueron lo kitsch, lo popular, la contemporanización de la vanguardia, la Ópera Bufa y la Creación Colectiva.

Así, en el presente texto abordaremos la forma en que la improvisación se convirtió en el mecanismo de creación más contundente durante el proceso, no sin ello exaltar la importancia de los elementos vestuario, escenografía, iluminación, música y maquillaje, temas que merecen ser abordados en profundidad, y por ello para cada uno dedicaremos la escritura de un capítulo.

\section{Sobre la improvisación}

La conceptualización de la práctica escénica es la búsqueda de una unidad estética, en la que los elementos que hacen posible la puesta teatral encuentran su génesis, tanto como las directrices que permiten el reconocimiento de los aspectos que problematizan el trabajo creativo.

En Colombia, un país que ha carecido de una tradición formativa en danza a nivel académico, los resultados obtenidos de su práctica actual o contemporáneo son obras que representan un trabajo realizado con la convicción personal del profesionalismo del creador, de este modo, las imágenes conseguidas por tal labor dan cuenta de una factura particular. El nuestro, fue un contexto donde los estudiantes demostraron los resultados de su práctica escénica pedagógica a través de propuestas que surgieron de un trabajo de exploración e investigación individual y colectiva que fue determinando en cada escena de la pieza, sus respectivos resultados, así se hicieron visibles diversos aspectos de nuestra realidad y de nuestro ser cultural.

La concentración de diferentes estéticas dio como resultado la afirmación de nuestra identidad transcultural, que se creó escénicamente a partir de la exaltación de la espontaneidad, de la improvisación como un fundamento de nuestro hacer a través de la experiencia pedagógica. Nuestras imágenes artísticas han sido desde el comienzo del proceso el testimonio vivo de las diferentes experiencias de vida traducidas al lenguaje escénico, donde la riqueza creativa fue el común denominador.

Por esto, hablar de procesos creativos desde la educación artística en el programa es, sobretodo, referirse al potencial creador y transformador 
de esta disciplina, capaz de servir de canalizadora de experiencias y sensaciones, permitiendo enfrentar los prejuicios y las convenciones para fomentar la autonomía creadora desde la identidad multicultural.

A través de las reflexiones que la producción escénica puedo suscitar, se evidenció el propósito de pensar la puesta en escena desde sus procesos de composición en nuestro contexto. A partir de esta perspectiva, daremos una mirada inicial a dicho dominio de la improvisación desde el panorama de la creación colectiva.

En Colombia se ha trabajado en el teatro con métodos de improvisación como base de la creación colectiva desde la década de 1960 en la que Enrique Buenaventura se convirtió en uno de sus máximos exponentes y seria el mismo quien enseñaría a varios académicos que ya habían muchos países en el mundo que asumirían el método de Creación Colectiva, el cual no es concretamente un método, como el de Konstantin Stanislavsky sino más bien algo muy experimental, una forma de engranar las piezas en un universo de puertas abiertas a la improvisación, a la experimentación.

Tales elementos han sido referentes constantes en la producción escénica hace ya algunos años, situación referenciada en varios textos, entre ellos los del antioqueño Oscar Vahos quien afirma "hemos optado por orientar nuestra búsqueda, implementando o enriqueciendo nuestras estrategias metodológicas fundamentados en la creación colectiva, herramienta muy avanzada en el teatro colombiano" (Vahos, 1998, p.100). En los montajes, el elemento de la improvisación hace parte primordial en la indagación por lenguaje corporal, intrínsecamente auténtico y particular, que compone la dramaturgia de cada actor, como dice Le Breton “... no hay ninguna ruptura cualitativa entre la carne del hombre y la del mundo" (Le Breton, 2002, p. 33). Dicha dramaturgia se traduce en escenas enteras apoyadas expresamente en la improvisación, creadas colectivamente a partir de ésta por el grupo de actores.

Así, la improvisación alcanzo cada vez una mayor relevancia como instrumento formativo y como herramienta práctica de integración multidisciplinaria. Por esto, la improvisación en la propuesta Rascosis irrumpió como un impulso, que desde el origen manifestó su necesidad de expresar lo profundamente humano, y en últimas, pretendió emerger por la vía de la potencia del movimiento así "el hombre es indiscernible 
del cuerpo que le otorga espesor y sensibilidad de su ser en el mundo" (Le Breton, 2002, p. 9).

La improvisación se manifestó como un instrumento de exploración, que nos sirvió como herramienta de expansión de posibilidades en el contexto extra-cotidiano del espacio escénico:

[La improvisación] La encuentro una muy buena compañía para la técnica, en el sentido de que, en combinación, construyen una mente más compleja. La improvisación lleva a una mayor profundidad de investigación porque es muy fácil frenarse ante las respuestas recibidas por la técnica. Una vez que puedes hacer algo correctamente, una vez que tienes la técnica en tu cuerpo, quizás alguna parte del proceso de investigación termine. Pero con la improvisación las preguntas no terminan nunca (Paxton, 1997, p. 27).

Otro carácter diferenciador de la improvisación es su naturaleza autónoma, o sea que, ella configura una composición en sí misma. La autonomía de la improvisación se consolida en la contemporaneidad a partir de la fragmentación de la unicidad del arte como lo afirma Margarita Calle Guerra "las derivas del arte animaron el giro operado por los primeros artistas modernos, con quienes se fragmenta la unicidad del arte, como afirmación del derecho a la autonomía y a la individualidad creativa" (Calle, 2006, p. 104).

La improvisación se presentó como la optimización del proceso compositivo, pues con ella los componentes (movimiento, música, cuerpo, espacio, imagen, texto, entre otros) lograron obtener la autenticidad que requieren a través de la espontaneidad que la misma improvisación implica.

En el proceso compositivo, los modos de abordar una puesta en escena y de desarrollarla cambian enormemente de un director a otro. En el contexto educativo se dan varias formas de dicho proceso. Algunos docentes poseen una idea plenamente estructurada y previamente concebida de la estructura del montaje que pretenden realizar antes de reunirse con el cuerpo de estudiantes, mientras que otros la perciben al guiar y observar las improvisaciones de los estudiantes, como fue nuestro caso, en tanto experimentan con las ideas dadas, otros desenvuelven un constructo general y luego toman decisiones sobre las composiciones específicas de estructuras generales al trabajar con los cuerpos de los educandos. 
Algunos utilizan extensos bocetos, dibujos, cartografías y notaciones. O sea, unos planifican y otros trabajan por instinto e improvisación como lo hicimos nosotros en este proceso.

Se entiende por improvisación en teatro, el arte de expresar o crear toda o parte de una composición en el momento del calor de la acción, en otras palabras, improvisar es un suceso de creación en tiempo presente, en el que existe un permanente estado de cambio que nos traslada hacia el oscuro abismo de lo inexplorado. Para una improvisación eficaz, se debieron comprender hondamente las convenciones específicas que el colectivo en pleno buscaba, así como el objetivo que se perseguía con esta tarea. Tales convenciones actuaron como una suerte de biblioteca mental, con secuencias efectivas de patrones coreográficos y movimientos que se fusionaron, modificaron y se emplearon como punto de partida para las creaciones. Estos recursos contribuyeron a que la puesta en escena sea rica en imágenes, a la vez que posibilitaron un espacio para la creatividad espontánea.

La composición escénica conforma la progresión de elementos (sistemas escénicos) que se superponen, lo que hace precisa la intención de armonizar y crear un orden entre los componentes que hacen posible la existencia concreta de la obra, su gesto particular. En este caso se dio paso a la creación de nuevos lenguajes, a la renovada escritura en el espacio escénico de una pieza cuyos referentes se hicieron desde el ahora bajo el prisma de la improvisación, susceptibles de transformación y exploración, otorgando una gama de posibilidades más amplia, cuya responsabilidad recayó en el colectivo de trabajo de cada pieza. De este modo, se hizo posible el encuentro de un lenguaje auténtico que se generó como movimiento de integración, más que como escisión en el devenir histórico de la tarea compositiva. Esto nos reafirmó que la improvisación debe ser una tarea de creación colectiva que reconozca en el trabajo de todos, las múltiples opciones que se pueden retroalimentar en el enriquecimiento que genera una propuesta con más matices.

La improvisación posibilitó hacer a un lado lo evidente, los referentes más inmediatos y recurrentes, permitió renunciar a los estereotipos y emprender la tarea de comenzar desde lo básico, lo elemental de las formas que el cuerpo y su dinámica refirieron sin predeterminaciones, logrando intenciones que nacieron de las relaciones directas del cuerpo 
del estudiante con la propuesta, el espacio y sus contextos específicos. Como ruta de enfrentamiento ante la sobrestimulación natural al que está expuesto el sujeto actual y que es si la forjadora del pensamiento prefabricado y la conducta homogénea, se hizo uso de la metáfora artística en cada imagen como acto de renuncia a lo próximo e inmediato, generando como producto la desmitificación de la acción recurrente como única respuesta.

La improvisación condujo a un proceso de indagación en las raíces del movimiento y su significación, así como en las relaciones posibles que la obra pudo sostener con las estructuras que la conformaban para elegir lo que, ante nuestro criterio y conocimiento artístico como directores/ docentes, fuese más comunicable y expresivo en tanto a la sensación estética que como colectivo buscábamos.

Por otro lado, improvisar requiere del autoconocimiento de las potencialidades y capacidades interpretativas del hacedor, para mediar y ordenar sus conocimientos y los de todo el grupo de trabajo al servicio de un proyecto concreto: la obra, tanto desde sus primeros esbozos, hasta el momento de la proyección frente al público. Es por esto que, dentro de la estructura de la improvisación de Rascosis, no se distribuyó el proceso en un orden jerárquico, vertical, que impidiera la autonomía de la labor profesional de los ejecutantes, ni fue un trabajo de cualificación, sino de diálogo y comunicación entre los que componían y desenvolvían el proceso.

Lo anterior no significó la desaparición o anulación de labores específicas dentro de la composición, tales como la de escenografía, iluminación, vestuario, comunicaciones, musicalización, maquillaje o dirección. Al contrario, cada actividad se reafirmó y dinamizó, en la medida en que los que se encargaron de ejecutar su oficio sobre el escenario propusieron y conformaron un equipo que operó como unidad. En este sentido, el estudiante proyectó su oficio a partir de la elección efectiva del momento exacto cuyo resultado fue el otorgamiento de la experiencia única que se capturó en un movimiento o gesto, tales circunstancias lo convirtieron en un símbolo de especial resonancia que contribuyó al lenguaje particular de la obra. De este modo, se permitió encontrar elementos con los que no se contaba y que hicieron que la pieza llegara hasta regiones que hubiesen sido indeterminadas en un diseño realizado antes de la condensación que la improvisación alienta. 
Este proceso sugiere la emergencia de las ideas gestadas por una pieza, por ello, la improvisación nutrió la composición de una forma vasta y potente permitiendo la ejecución de la propuesta, en la que el cúmulo de experiencias, constituyente del horizonte vital y profesional de cada estudiante, yuxtapuso finalmente las formas. Por tal motivo, la jerarquía del proceso de composición se deformó y dio paso a una labor de grupo que exigió de todos una plena participación e integración en el camino donde se obtuvieron los materiales para la pieza. Esto alejó al estudiante de su posición de simple subordinado al interés del director/docente y lo inscribió en la tarea decisiva de componer, lo que sobrepasó el reconocimiento de una única mirada en la elaboración del montaje.

De tal manera, la formación emotiva del intérprete entró a ser parte de la propuesta compositiva y narrativa de la pieza. Los sujetos operaron en conjunción con un proyecto que se tornó expresión unívoca de criterio, surgido de la multiplicidad propositiva del colectivo de trabajo.

Esto hizo posible el fortalecimiento de la identidad estética particular de la propuesta, a través de los resultados de la instauración de una vía basada en, lo que con total asertividad se podría llamar improvisación. Lo que significa que el producto encontrado dependió, en gran medida, del buen proceso individual y colectivo, fruto de la creación que se inclinó hacia la formación particular de cada estudiante como docente/ artista, y de la participación e interrelación en dicho proceso.

Operó entonces, una condición propia y única de cuerpo de trabajo, la cual podríamos asemejar a la condición de particularidad que MerleauPonty ${ }^{1}$ otorga a la unidad del cuerpo, que tanto aquí como en la composición de una obra de arte, llega a ser la resulta de sus experiencias y de dicha particularidad, que se traducen finalmente en el montaje de la obra.

El descubrimiento e implementación de mecanismos expresivos y narrativos devinieron entonces, de una tarea más allá de la mera ins-

1 Maurice Merleau-Ponty, filósofo francés cuyo trabajo y disertaciones sobre el cuerpo y la obra de arte sirven de interesante materia para la cuestión estética y conceptual, en este caso de la danza. Ver de este autor: "La fenomenología de la percepción", Edición 62, Barcelona, 1975. 
piración. Investigación, estudio y experimentación (teoría-práctica e investigación) fueron los componentes necesarios que todo el equipo de trabajo visualizó para alcanzar satisfactorios resultados, esto incluye a los estudiante, los docentes acompañantes en el proceso y el espectador, que es en últimas quien da sentido al resultado estético de la labor escénica; de otra manera, omitiendo los componentes expuestos, la obra se hubiese limitado a asuntos formales.

La improvisación le dio a cada estudiante la oportunidad de acercarse a códigos de representación universales, para fijar la impronta particular de sus condiciones como profesional y como sujeto de su realidad, dice Le Breton (2002): “cada sociedad esboza, en el interior de su visión del mundo, un saber singular sobre el cuerpo: sus constituyentes, sus usos, sus correspondencias, etc., le otorgan sentido y valor" (p. 8), hacer que tales códigos fueran resignificados por el artista/educando, desde el estudio de lo cotidiano, transforma paulatinamente un paradigma de movimiento, parafraseando a Le Breton (2002, p. 9), como un universo cambiante de significaciones.

Como ya se mencionó, la improvisación ha desempeñado un rol sobresaliente en el impulso de las artes escénicas en nuestro contexto, ya que puede ser un material temático específico con unas consignas definidas. No se trata solo de liberar la imaginación escénicamente, sino de llegar a esta praxis por medio de una técnica decantada cuidadosamente que tiene sus principios epistemológicos en el paradigma de la posmodernidad desde el punto de vista escénico. Así, las reglas no están particularmente dadas sino que pueden variar. A esta manera de trabajo le llamaremos improvisación; para la cual, los elementos escénicos aportan a las artes escénicas entes vitales (Heidegger, 1974, p. 165), puestos al servicio del movimiento.

La improvisación vista desde la práctica escénica es, de una manera muy general, la caracterización de un conflicto en un espacio y un tiempo determinado, o un asunto de resoluciones teatrales donde el estudiante es el elemento dinámico, el ejecutante que hace posible la materialización del conflicto. En este caso particular, cada estudiante partió de un pretexto en común que tomo forma por medio de la sensación que deviene de la relación con la cultura popular antioqueña. El proyecto cobró vida por la habilidad que tienen los educandos en el momento de la improvisación y por los recursos escénicos que utilizaron. 
Dentro de esta propuesta se contó con la libertad de crear buscando las justificaciones conceptuales, temporales y espaciales, explorando el texto del cuerpo y el espacio, y transformando la improvisación como herramienta del proceso de formación. La investigación pretendió de la consecución de la calidad en las realizaciones de las escenas, lo que implicó una claridad en la expresión de los aspectos que se consideraron significativos para la realización.

La riqueza cultural del país ofrece innumerables posibilidades creativas y de exploración escénica; sus opciones se manifiestan como un acervo artístico prismático, en el cual podemos reconocer la pluralidad de las tradiciones y mirarlas a través de un lente de propuestas contemporáneas, lo que establece un lenguaje particular de nuestras formas de ver el mundo como referentes propios, reflejos de formas universales, al respecto afirma Le Breton " Cada sujeto existe sólo por su relación con los demás. El hombre es sólo un reflejo. Obtiene su espesor, su consistencia, de la suma de vínculos con sus compañeros" (Le Breton, 2002, p.17). Por esto, en Rascosis perfilamos lenguajes interpretativos propios que condensaron nuestra realidad cultural.

La improvisación se transfiguró en un metalenguaje que nombró al cuerpo en la condición humana de los signos a partir de un lenguaje propio, o sea, una caída en el círculo de lo nombrado a través de una sensación (Le Breton, 2002, p. 9), el eros y el thanatos individual nombraron el espesor de nuestra singularidad.

Dicha condición de improvisación debe entenderse como el recurso vital de la puesta en escena a manera de enclaves buscando sentar las bases de la estructura final. Del mismo modo, comprender la improvisación como un instrumento de navegación, una brújula indispensable para llegar a la puesta en escena, fue un imperativo de claridad para todos los participantes del proceso, entender que no es otra cosa que encarnar la condición de creador-intérprete que requiere un cuerpo que posea las condiciones no sólo físicas y técnicas, sino también teóricas, para dar soporte a la propuesta artística en la que los sentidos actuarían como un delta donde encontraríamos diversos lenguajes para la composición, fue más que necesario.

La improvisación brindó la posibilidad de acopiar intereses y coincidencias entre sí, posibilitó además, una fragmentación discontinua en el 
proceso de creación que fue contemplada como mosaico, lo que permitió el empleo de circunstancias de contexto cambiantes, que desembocaron en determinadas instancias de creación, producción y control para el resultado esperado.

Interrogar directamente el contexto en el que la búsqueda de una improvisación parte del creador, cuyas posibilidades están inscritas en su tejido de vida, implicó que la imagen y el movimiento corporal se presentaran como los primogénitos de la puesta en escena, cuyo discurso cinético puso en evidencia al mundo moderno como representación, procurando estructuras insondables y duraderas, confirmando así que "el cuerpo moderno pertenece a un orden diferente, implica una ruptura del sujeto con los otros (una estructura social de tipo individualista)" (Le Breton, 2002, p. 8).

Fue pues la improvisación, la expresión de lateralidades y modos, cuya mayor o menor carga está inundada por el estudiante creador en contraste con la centralidad de la estructura de representación indicada por el director, quién generó un escenario preparado para satisfacer las ambiciones, en el cual se indagaría a sí mismo como espacio para la representación.

Conviene señalar aquí la dimensión espacio temporal del hecho escénico que se registró dentro del contexto de nuestra puesta en escena, que fue más que una tendencia acrobático dancística o teatral, cuya movilidad valoró un sinnúmero de posibilidades entre las que cupieron la descodificación, las arritmias, las intermitencias, las urgencias o relentizaciones de cualquier orden, y que permitieron una experiencia donde se unificó la pluralidad para estallar en el desborde de los compuestos de interpretación de la puesta en escena clásica.

La utilización de la improvisación en el ámbito pedagógico, nos permitió entrar en contacto con las expresiones auténticas del estudiante creador que fueron la materia prima de la representación, en donde los caracteres de éste se consideran inmanentes y manifiestos en la totalidad de la pieza elaborada.

El estudiante obtuvo su condición, basado en la posesión de un capital figurado en el que se admitió argumentar ante sí mismo y ante los demás su trabajo de improvisación, en el cual se entrecruzaron formaciones e 
informaciones de tipo estético, humano e intelectual, mostrando allí su originalidad y atravesando el registro simbólico que evoca su sentido primigenio.

Los códigos propuestos por el creador entrecruzaron la multiplicidad interminable de la práctica artística, lo que requirió decantar una estética en la puesta en escena. Así, el espacio gozó de una pluralidad excepcional, propuesta por las acciones del creador; el conjunto de improvisaciones permitió emerger lógicas contenidas en puesta en escena, como producto.

Los aspectos que se vincularon a la indagación generaron etapas para optimizar el resultado de la puesta en escena. Fue allí donde los criterios de aceptabilidad de la improvisación o sus reglas se flexibilizaron como instrumentos construibles, que operaron para dar resultados en la arquitectura de la obra.

A manera de conclusión se nos hace necesario mencionar que las transformaciones personales fueron blanco de hondos cuestionamientos en torno a la intensión sensata de la labor como docente. Esto trajo el volcamiento de experiencias que antes no disponían de un posible emplazamiento, de esta manera, cada partícipe del proyecto Rascosis se encargó y de una serie de labores indispensables en la práctica que todo maestro en artes en la educación de hoy debe reconocer como acciones pertinentes.

La idea romántica del artista como un ser exquisito y lejano con obras cargadas de bondad y un aura sublime dentro de los parámetros de la estética clásica fueron remplazados por un proyecto colectivo donde cada estudiante asumió la transformación socioeducativa desde sí mismo, reafirmándolo como un acto que debe ocurrir desde sí hacia los demás. Por tal razón, Rascosis propuso una pausa a las prácticas naturales del proceso de profesionalización a cambio de hacer un auto análisis enfocado en los modos de enseñar, el sentido de la vocación docente y del conocimiento renovado del arte antes que proseguir con un posible hacer no reflexionado y sin aporte al mundo de la educación. 


\section{Referencias}

Calle Guerra, A. (2006). Derivas del arte. Transfiguraciones del cuerpo, movimientos de la experiencia. En Colombia Habladurías. Programa Editorial Universidad Autónoma de Occidente

Heidegger, M. (1974). Qué es metafísica. Argentina: Editorial Siglo XX.

Le Breton, D. (2002). Antropología del cuerpo y modernidad. Buenos Aires: Editorial Nueva Visión.

Merleau-Ponty, M. (1975). La fenomenología de la percepción. Barcelona: Edición 62.

Paxton, S. (1997). Contredanse/Nouvelles de Danse. Bruselas: Editado por Agnès Benoit.

Vahos, O. (2007). Danza: Ensayos. Medellín: Editorial Producciones Infinito. 